\title{
Safety and efficacy of US-approved viscosupplements for knee osteoarthritis: a systematic review and meta-analysis of randomized, saline-controlled trials
}

\author{
This article was published in the following Dove Press journal: \\ Journal of Pain Research \\ 7 May 2015 \\ Number of times this article has been viewed
}

\section{Vibeke Strand' \\ Louis F Mclntyre ${ }^{2}$ \\ William R Beach ${ }^{3}$ \\ Larry E Miller ${ }^{4,5}$ \\ Jon E Block ${ }^{5}$}

'Stanford University School of Medicine, Palo Alto, CA, USA; ${ }^{2} \mathrm{New}$ York University Medical Center, White Plains, NY, USA; ${ }^{3}$ Tuckahoe Orthopaedics, Richmond, VA, USA; ${ }^{4}$ Miller Scientific Consulting, Inc., Asheville, NC, USA; ${ }^{5}$ The Jon Block Group, San Francisco, CA, USA
Correspondence: Larry E Miller Miller Scientific Consulting, Inc., I 854 Hendersonville Road \#23I, Asheville, NC 28803, USA

$\mathrm{Tel}+\mathrm{I} 8284501895$

Email larry@millerscientific.com
Background: Intra-articular injection of hyaluronic acid is a common, yet controversial, therapeutic option for patients with knee osteoarthritis (OA). The purpose of this research was to determine the safety and efficacy of US-approved viscosupplements for symptomatic knee OA.

Methods: We searched MedLine and EMBase for randomized, sham-controlled trials evaluating safety and/or clinical efficacy of US-approved viscosupplements in patients with symptomatic knee OA. Knee pain severity and knee joint function were assessed at 4 to 13 weeks and 14 to 26 weeks. Safety outcomes included serious adverse events, treatment-related serious adverse events, patient withdrawal, and adverse event-related patient withdrawal occurring at any time during follow-up.

Results: A total of 29 studies representing 4,866 unique patients (active: 2,673, control: 2,193) were included. All sham-controlled trials used saline injections as a control. Viscosupplementation resulted in very large treatment effects between 4 and 26 weeks for knee pain and function compared to preinjection values, with standardized mean difference values ranging from 1.07 to 1.37 (all $P<0.001$ ). Compared to controls, standardized mean difference with viscosupplementation ranged from 0.38 to 0.43 for knee pain and 0.32 to 0.34 for knee function (all $P<0.001$ ). There were no statistically significant differences between viscosupplementation and controls for any safety outcome, with absolute risk differences of $0.7 \%$ ( $95 \%$ confidence interval $[\mathrm{CI}]:-0.2$ to $1.5 \%)$ for serious adverse events, $0 \%(95 \% \mathrm{CI}$ : -0.4 to $0.4 \%)$ for treatment-related serious adverse events, $0 \%(95 \% \mathrm{CI}:-1.6$ to $1.6 \%)$ for patient withdrawal, and $0.2 \%$ (95\% CI: -0.4 to $0.8 \%$ ) for adverse event-related patient withdrawal.

Conclusion: Intra-articular injection of US-approved viscosupplements is safe and efficacious through 26 weeks in patients with symptomatic knee OA.

Keywords: hyaluronic acid, intra-articular, viscosupplementation

\section{Introduction}

Osteoarthritis (OA) is a common degenerative disease in older adults that is characterized by joint pain and dysfunction due to progressive subchondral bone damage, articular cartilage loss, inflammation/synovitis, and osteophyte formation. ${ }^{1}$ Hyaluronic acid (HA) is an integral component of synovial fluid that acts as a joint lubricant during shear stress and a shock absorber during compressive stress. In the setting of knee $\mathrm{OA}$, a marked reduction in concentration and molecular weight of endogenous HA ultimately leads to reduced viscoelastic properties of synovial fluid and induction of proinflammatory pathways. $^{2}$ Intra-articular injection of exogenous HA is intended to 
replace this $\mathrm{OA}$-induced deficit and stimulate production of endogenous HA, ${ }^{3}$ which may alleviate symptoms of knee OA via multiple pathways including inhibition of chondrodegradative enzymes and inflammatory processes, stimulation of chondrocyte metabolism, and synthesis of articular cartilage matrix components. ${ }^{4}$

Viscosupplements, involving the intra-articular injection of HA, are classified as medical devices in the US, under the regulation of the Food and Drug Administration. Since medical devices are regulated by different regulatory bodies across countries, it is relevant to assess the safety and efficacy profile of such products by country. The purpose of this systematic review and meta-analysis of randomized controlled trials was to determine the safety and efficacy of US-approved viscosupplements for symptomatic knee OA. A secondary rationale for performing the current meta-analysis was that, despite extensive evidence to the contrary, ${ }^{5-11}$ the safety of viscosupplementation for knee OA has recently been called into question. ${ }^{12}$

\section{Methods}

\section{Data sources}

The study was performed according to the Preferred Reporting Items for Systematic Reviews and Meta-analyses (PRISMA) (File S1). ${ }^{13}$ We searched MedLine and EMBase for randomized, sham-controlled trials of intra-articular HA (IAHA) injection for treatment of knee OA using a combination of study design-, treatment-, and disease-specific keywords and Medical Subject Headings terms.

\section{Study selection}

No date restrictions were applied to the searches. Main inclusion criteria were injection of a US-approved HA product; randomized, sham-control study design; primary diagnosis of knee OA; identical treatment and follow-up conditions between IAHA and sham-control groups; and at least one extractable efficacy or safety outcome. Trials were excluded if concomitant interventional therapies were uniformly administered; were published in nonEnglish language journals; or data were available only from abstracts, conference proceedings, websites, or personal communication. The details of the MedLine search strategy are listed in File S2. The syntax for EMBase was similar but adapted as necessary. Additionally, reference lists of included papers and relevant meta-analyses were manually searched. The final search was conducted in December 2013.

\section{Data extraction}

Data were extracted from eligible peer-reviewed articles by one author (LEM) and verified by a second author (JEB). Data extraction discrepancies between the two coders were determined by discussion and consensus. The following variables were recorded in standardized, pretested data extraction forms: general manuscript information (author, institution name and location, journal, year, volume, page numbers), patient characteristics (sex, age, body mass index [BMI], symptom duration, Kellgren-Lawrence grade), study characteristics (study quality, sample size, blinding assessment, HA trade name, number of injections and cycles, industry funding), efficacy outcomes (knee pain, knee function), and safety outcomes (serious adverse events [SAEs], treatmentrelated SAEs, patient withdrawals, patient withdrawals due to adverse events [AEs]).

Methodologic quality of studies was assessed using the Jadad score, ${ }^{14}$ rated from 0 to 5 according to the presence of three key methodological features: randomization, blinding, and patient accountability. We defined a higher-quality trial as Jadad score $\geq 3$. Main outcomes included pain severity, joint function, and safety variables. Pain severity and joint function data were extracted from papers in a nonbiased manner using the knee OA outcome meta-analysis hierarchy of Juhl et al. ${ }^{15}$ Briefly, the first variables to be extracted from this prioritized list included the Western Ontario and McMaster Universities Arthritis Index (WOMAC) pain subscale, pain during activity, and pain during walking for pain severity effects and WOMAC function subscale, physical composite summary, and physical function domain scores of the short form (SF)-36, SF-12, or SF-8. This hierarchy contains eight potential pain variables and four potential function variables. If none of the variables in this hierarchy were reported, we then used relevant pain and physical function assessments reported in the studies.

Due to the variation in reporting the postinjection pain and function trajectories, we a priori stratified data into two postinjection time windows: 4 to 13 weeks and 14 to 26 weeks. Efficacy data reported outside of these windows were excluded. If multiple pain or function effects within a given window were reported in a specific trial, the final value for each was extracted for analysis purposes. Safety outcomes included SAEs, treatment-related SAEs, withdrawals, and AE-related withdrawals occurring at any time during follow-up.

\section{Data synthesis}

A random effects meta-analysis model was selected a priori for all analyses. For each efficacy outcome, we calculated 
two separate effect size statistics in each time window: a) pretreatment to posttreatment standardized mean difference (SMD) for IAHA, and b) SMD for IAHA versus control. For reference, SMD values of $0.2,0.5,0.8$, and 1.0 are defined as small, medium, large, and very large effect sizes, respectively. ${ }^{16}$ For each safety outcome, the absolute risk difference (RD) was selected since this statistic considers data from all studies, including zero total event trials. ${ }^{17}$ When a single control group was compared with multiple treatment groups within a study, the sample size of the control group entered into the meta-analysis was adjusted based on the number of treatment groups. ${ }^{18}$ Forest plots were used to visually assess effect sizes and corresponding 95\% confidence intervals (CIs) across studies. We used the $I^{2}$ statistic to estimate heterogeneity of treatment effects with values of $\leq 25 \%, 50 \%$, and $\geq 75 \%$ representing low, moderate, and high inconsistency, respectively. ${ }^{19}$ Publication bias was visually assessed with funnel plots and quantitatively assessed using Egger's regression test. ${ }^{20}$ Predefined subgroup analyses were undertaken to quantify the relationship of individual moderators on safety and efficacy outcomes. A priori, we identified the following subgroups as possible moderators of heterogeneity: female sex $\geq 67 \%$ versus $<67 \%$, age $\geq 65$ years versus $<65$ years, BMI $\geq 30 \mathrm{~kg} / \mathrm{m}^{2}$ versus $<30 \mathrm{~kg} / \mathrm{m}^{2}$, symptom duration $\geq 5$ years versus $<5$ years, Kellgren-Lawrence grade $\geq 3$ versus $<3$, total sample size $\geq 100$ versus $<100$, Jadad score $\geq 3$, and presence or absence of industry funding. $P$-values were two-sided with a significance level $<0.05$. All analyses were performed using Comprehensive Meta-analysis (version 2.2; Biostat, Englewood, NJ, USA).

\section{Results}

\section{Study selection}

After screening 1,653 records for eligibility, 29 randomized, saline-controlled trials ${ }^{21-49}$ reporting 38 treatment effects from 4,866 unique patients (IAHA: 2,673, control: 2,193) were included in the meta-analysis. The most common reasons for study exclusion included lack of a sham control group, nonrandomized design, or use of HA products not approved in the US. All included trials used a saline control vehicle. A flow diagram of study identification and selection is shown in Figure 1.

\section{Patient characteristics}

Baseline patient characteristics were similar between the IAHA and control groups (Table 1). Approximately two in

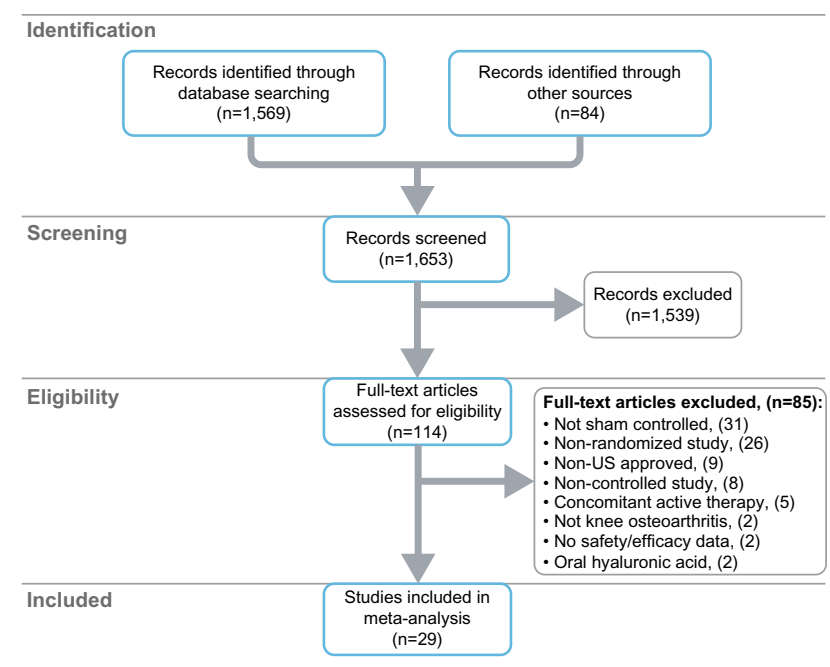

Figure I PRISMA flow diagram.

Abbreviation: PRISMA, Preferred Reporting Items for Systematic Reviews and Meta-analyses.

three patients were female with a mean age of 65 and 62 years in the viscosupplement and control groups, respectively. Patients were typically overweight or obese and presented with OA symptom duration of 4 years on average, with moderate radiographic disease severity.

\section{Study characteristics}

Most (28 of 29) studies utilized an unblinded injector, with patients (26 of 29) and outcome assessors (21 of 29) typically fully blinded. The most commonly studied viscosupplements were Hyalgan (18), Synvisc (nine), Supartz/ Artzal (six), Orthovisc (three), Gel-One (one), and EUFLEXXA (one). Although Artzal is not marketed in the US, the formulation is identical to that of Supartz and, therefore, was included in the meta-analyses. The total number of injections received by patients ranged from one to five, with the exception of the study of Jubb et al, ${ }^{36}$ where patients received three cycles of three injections, each with

Table I Baseline patient characteristics

\begin{tabular}{lll}
\hline Characteristics & Viscosupplementation & Saline \\
\hline Patients, n & 2,673 & 2,193 \\
Age, yr, mean (min-max) & $65(53-72)$ & $62(53-73)$ \\
$\begin{array}{l}\text { Female, \%, median (min-max) } \\
\text { Body mass index, kg/m², }\end{array}$ & $64(27-92)$ & $65(22-100)$ \\
$\begin{array}{l}\text { mean (min-max) } \\
\text { Symptom duration, yr, }\end{array}$ & $4.9(1.0-9.1)$ & $29(25-33)$ \\
$\begin{array}{l}\text { mean (min-max) } \\
\text { Kellgren-Lawrence grade, } \\
\text { mean (min-max) }\end{array}$ & $2.5(1.9-3.0)$ & $4.3(0.8-8.5)$ \\
\hline
\end{tabular}

Abbreviations: max, maximum; min, minimum; yr, years. 
efficacy evaluated after the first cycle. All included studies used phosphate-buffered saline as the control, with the saline volume identical between IAHA and control groups. Only two (7\%) studies were clearly independent of industry support (Table 2).

\section{Study quality assessment}

Overall, the methodological quality of studies was medium, with a median Jadad score of 3 (range: 2 to 5). Only four $(14 \%)$ studies were rated with a Jadad score $\geq 4$. The method of randomization and blinding were adequately reported in three (10\%) and four (14\%) studies, respectively.
Patient accountability was adequately detailed in 27 (93\%) studies (Table 3).

\section{Viscosupplementation efficacy versus pretreatment}

Intra-articular viscosupplement injection resulted in very large treatment effects for knee pain and knee function compared to pretreatment values. The SMD for knee pain was 1.37 (95\% CI: 1.12 to 1.61$)$ at 4 to 13 weeks and 1.14 (95\% CI: 0.89 to 1.39 ) at 14 to 26 weeks (both $P<0.001$ ) (Files S3 and S4). Treatment effects for knee function remained very large although slighter lower with SMDs of 1.16 (95\% CI: 0.99

Table 2 Characteristics of studies included in meta-analysis

\begin{tabular}{|c|c|c|c|c|c|c|c|}
\hline \multirow[t]{2}{*}{ Study } & \multicolumn{4}{|c|}{ Blinding $^{\mathrm{a}}$} & \multicolumn{3}{|c|}{ Viscosupplementation details } \\
\hline & Patient & Injectors & $\begin{array}{l}\text { Outcome } \\
\text { assessors }\end{array}$ & $\begin{array}{l}\text { Trade }^{b} \\
\text { name }\end{array}$ & $\begin{array}{l}\text { Total no } \\
\text { injections }\end{array}$ & $\begin{array}{l}\text { Total no } \\
\text { cycles }\end{array}$ & $\begin{array}{l}\text { Industry- } \\
\text { funded study? }\end{array}$ \\
\hline Altman and Moskowitz, 199821 & 1 & 0 & $\mathrm{I}$ & Hyalgan & 5 & $\mathrm{I}$ & Yes \\
\hline Altman et al, $2009^{22}$ & 1 & 0 & 1 & EUFLEXXA & 3 & 1 & Yes \\
\hline \multirow[t]{2}{*}{ Bragantini et al, $1987^{23}$} & 0 & 0 & 0 & Hyalgan & 3 & 1 & Unclear \\
\hline & I & 0 & 0 & Hyalgan & 3 & I & \\
\hline Brandt et al, $200 \mathrm{I}^{24}$ & 1 & 0 & I & Orthovisc & 3 & I & Yes \\
\hline Bunyaratavej et al, $200 \mathrm{I}^{25}$ & I & 0 & I & Hyalgan & 4 & I & Unclear \\
\hline \multirow{3}{*}{ Carrabba et al, $1995^{26}$} & 1 & 0 & 1 & Hyalgan & 5 & 1 & Unclear \\
\hline & & & & & 3 & & \\
\hline & & & & & I & & \\
\hline Cubukçu et al, $2005^{27}$ & 0 & 0 & 0 & Synvisc & 3 & I & Unclear \\
\hline Day et al, $2004^{28}$ & 1 & 0 & I & Artzal & 5 & 1 & Yes \\
\hline DeCaria et al, $2012^{29}$ & I & 0 & 0 & Hyalgan & 3 & I & No \\
\hline Diracoglu et al, $2009^{30}$ & 1 & 0 & 1 & Synvisc & 4 & 1 & Unclear \\
\hline Grecomoro et al, $1987^{31}$ & 0 & 0 & 0 & Hyalgan & 3 & 1 & Unclear \\
\hline Henderson et al, $1994^{32}$ & I & 0 & 1 & Hyalgan & 5 & 1 & Unclear \\
\hline Huang et al, $20 \mathrm{II}^{33}$ & 1 & 0 & I & Hyalgan & 5 & 1 & Yes \\
\hline Huskisson and Donnelly, $1999^{34}$ & 1 & 0 & 1 & Hyalgan & 5 & 1 & Unclear \\
\hline Jørgensen et al, $2010^{35}$ & 1 & 0 & 1 & Hyalgan & 5 & 1 & Yes \\
\hline Jubb et al, $2003^{36}$ & 1 & 0 & 1 & Hyalgan & $3(9)^{c}$ & $I(3)^{c}$ & Yes \\
\hline \multirow[t]{2}{*}{ Karlsson et al, $2002^{37}$} & I & 0 & I & Artzal & 3 & 1 & Yes \\
\hline & & & & Synvisc & 3 & I & \\
\hline \multirow[t]{2}{*}{ Kotevoglu et al, $2006^{38}$} & 1 & 0 & 1 & Orthovisc & 3 & 1 & Unclear \\
\hline & & & & Synvisc & & & \\
\hline Kul-Panza and Berker, $2010^{39}$ & 1 & 0 & I & Orthovisc & 3 & 1 & Unclear \\
\hline Lohmander et al, $1996^{40}$ & I & 0 & I & Artzal & 5 & I & Yes \\
\hline Lundsgaard et al, $2008^{41}$ & 1 & 0 & 1 & Hyalgan & 4 & 1 & No \\
\hline \multirow[t]{2}{*}{ Petrella et al, $2008^{42}$} & 1 & 0 & 0 & Synvisc & 3 & 1 & Unclear \\
\hline & & & & Hyalgan & & & \\
\hline Puhl et al, $1993^{43}$ & 1 & 0 & 1 & Artzal & 5 & 1 & Yes \\
\hline \multirow[t]{2}{*}{ Rolf et al, $2005^{44}$} & I & 0 & I & Synvisc & 3 & I & Yes \\
\hline & 1 & 0 & I & Artzal & 3 & I & Yes \\
\hline Sala and Miguel, $1995^{49}$ & 1 & 0 & 0 & Hyalgan & 5 & 1 & Unclear \\
\hline \multirow[t]{2}{*}{ Scale et al, $1994^{45}$} & 1 & 0 & 1 & Synvisc & 2 & 1 & Yes \\
\hline & I & 0 & 1 & Synvisc & 3 & 1 & \\
\hline Strand et al, $2012^{46}$ & I & 0 & I & Gel-One & 1 & I & Yes \\
\hline Wobig et al, $1998^{47}$ & 1 & I & 1 & Synvisc & 3 & I & Yes \\
\hline Wu et al, $1997^{48}$ & 1 & 0 & 0 & Artzal & 5 & I & Unclear \\
\hline
\end{tabular}

Notes: ${ }^{2}$ Assessment of blinding adequacy was independent of text description; ' ${ }^{b}$ Artzal is categorized as a US marketed product; Although Artzal is not marketed in the US, the formulation is identical to Supartz, which is marketed in the US; 'one cycle of three injections each for safety evaluation. 
Table 3 Assessment of study quality using Jadad scale

\begin{tabular}{|c|c|c|c|c|}
\hline Study & Randomization & Blinding & Accountablility & Total score \\
\hline Altman and Moskowitz, 199821 & I & 1 & I & 3 \\
\hline Altman et al, $2009^{22}$ & I & 1 & 1 & 3 \\
\hline Bragantini et al, $1987^{23}$ & I & I & I & 3 \\
\hline Brandt et al, $200 \mathrm{I}^{24}$ & I & 2 & I & 4 \\
\hline Bunyaratavej et al, $200 \mathrm{I}^{25}$ & I & I & 0 & 2 \\
\hline Carrabba et al, $1995^{26}$ & I & I & I & 3 \\
\hline Cubukçu et al, $2005^{27}$ & I & 0 & I & 2 \\
\hline Day et al, $2004^{28}$ & I & I & I & 3 \\
\hline DeCaria et al, $2012^{29}$ & I & I & I & 3 \\
\hline Diracoglu et al, $2009^{30}$ & I & I & I & 3 \\
\hline Grecomoro et al, $1987^{31}$ & I & I & I & 3 \\
\hline Henderson et al, $1994^{32}$ & I & I & I & 3 \\
\hline Huang et al, 20I I3 & I & 1 & I & 3 \\
\hline Huskisson and Donnelly, $1999^{34}$ & I & I & I & 3 \\
\hline Jørgensen et al, 2010 $0^{35}$ & I & I & I & 3 \\
\hline Jubb et al, $2003^{36}$ & I & I & I & 3 \\
\hline Karlsson et al, $2002^{37}$ & I & I & I & 3 \\
\hline Kotevoglu et al, $2006^{38}$ & I & I & I & 3 \\
\hline Kul-Panza and Berker, 201039 & I & I & 1 & 3 \\
\hline Lohmander et al, $1996^{40}$ & I & I & I & 3 \\
\hline Lundsgaard et al, $2008^{41}$ & 2 & 2 & I & 5 \\
\hline Petrella et al, $2008^{42}$ & I & I & I & 3 \\
\hline Puhl et al, $1993^{43}$ & 2 & 2 & I & 5 \\
\hline Rolf et al, $2005^{44}$ & I & I & I & 3 \\
\hline Sala and Miguel, $1995^{49}$ & I & I & I & 3 \\
\hline Scale et al, $1994^{45}$ & I & I & 0 & 2 \\
\hline Strand et al, $2012^{46}$ & 2 & 2 & I & 5 \\
\hline Wobig et al, $1998^{47}$ & I & I & I & 3 \\
\hline Wu et al, $1997^{48}$ & I & I & I & 3 \\
\hline
\end{tabular}

to 1.34 ) and 1.07 (95\% CI: 0.84 to 1.30 ), respectively (both $P<0.001$ ) (Files S5 and S6). There was high heterogeneity $\left(I^{2}=74 \%\right.$ to $92 \%$, all $\left.P<0.001\right)$ for all treatment effects, with evidence of publication bias for knee pain (Files S7 and S8), but not knee function (Files S9 and S10), in both analysis windows.

\section{Viscosupplementation efficacy versus saline control}

Compared to controls, the SMD for knee pain was 0.43 (95\% CI: 0.26 to 0.60$)$ at 4 to 13 weeks (File S11) and 0.38 (95\% CI: 0.21 to 0.55 ) at 14 to 26 weeks (Figure 2) (both $P<0.001)$. Knee function SMD was 0.34 (95\% CI: 0.16 to 0.51 ) and 0.32 (95\% CI: 0.18 to 0.45$)$, respectively, at the same time intervals (both $P<0.001$ ) (File S12; Figure 3). Heterogeneity among studies was high for knee pain $\left(I^{2}=73 \%\right.$ to $75 \%$, both $P<0.001$ ) and moderate for knee function ( $I^{2}=54 \%$ to $69 \%$, both $P<0.01$ ). Publication bias was evident for both knee pain treatment effects (Files S13 and S14) and for knee function at 4 to 13 weeks (File S15), but not for knee function at 14 to 26 weeks (File S16).

\section{Viscosupplementation safety versus saline control}

There were no statistically significant RDs between viscosupplementation and controls for any safety outcome. The risk of SAEs was similar between viscosupplementation and saline ( $\mathrm{RD}=0.7 \%, 95 \% \mathrm{CI}:-0.2 \%$ to $1.5 \%, P=0.12$ ) (Figure $4)$. No SAE in any trial was related to injection of viscosupplement or saline. The risk of patient withdrawal from the study for any reason was identical between treatment groups $(\mathrm{RD}=0.0 \%, 95 \% \mathrm{CI}:-1.6 \%$ to $1.6 \%, P=1.0)$ (File S17). The risk of patient withdrawal due to an AE was also similar with viscosupplementation versus control $(\mathrm{RD}=0.2 \%, 95 \%$ $\mathrm{CI}$ : $-0.4 \%$ to $0.8 \%, P=0.46$ ) (Figure 5 ). There was minimal heterogeneity in safety outcomes among studies (all $I^{2}=0 \%$ ) with no evidence of publication bias for any safety outcome (Files S18-S20).

\section{Subgroup analyses}

We performed predefined subgroup analyses to observe the influence of study- and patient-related characteristics on knee pain, knee function, and SAEs. Study-design factors, 
Study name

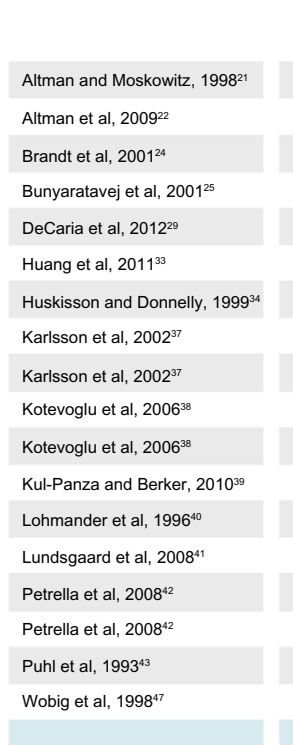

Statistics for each study

\begin{tabular}{cccc} 
SMD & $\begin{array}{c}\text { Lower } \\
\text { limit }\end{array}$ & $\begin{array}{c}\text { Upper } \\
\text { limit }\end{array}$ & $P$-value \\
0.277 & 0.012 & 0.543 & 0.041 \\
0.152 & -0.021 & 0.324 & 0.085 \\
\hline 0.400 & 0.059 & 0.741 & 0.021 \\
0.575 & 0.003 & 1.146 & 0.049 \\
\hline 0.787 & 0.044 & 1.529 & 0.038 \\
\hline 0.404 & 0.122 & 0.685 & 0.005 \\
\hline 0.630 & 0.181 & 1.079 & 0.006 \\
\hline-0.184 & -0.584 & 0.216 & 0.367 \\
-0.074 & -0.475 & 0.327 & 0.718 \\
\hline 0.827 & 0.012 & 1.642 & 0.047 \\
\hline 0.820 & 0.012 & 1.628 & 0.047 \\
\hline 0.360 & -0.229 & 0.949 & 0.231 \\
\hline 0.090 & -0.196 & 0.375 & 0.537 \\
\hline-0.289 & -0.599 & 0.021 & 0.067 \\
\hline 1.470 & 0.935 & 2.005 & 0.000 \\
\hline 0.690 & 0.197 & 1.183 & 0.006 \\
\hline 0.328 & 0.046 & 0.611 & 0.023 \\
\hline 0.786 & 0.391 & 1.182 & 0.000 \\
\hline 0.381 & 0.208 & 0.554 & 0.000 \\
\hline & & & \\
\hline & & & \\
\hline
\end{tabular}

SMD and $95 \% \mathrm{Cl}$

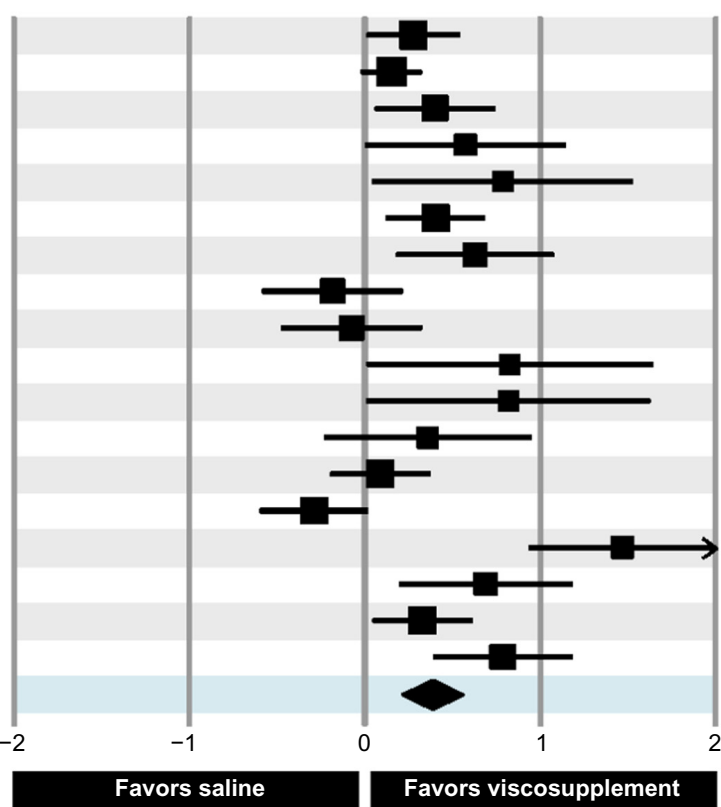

Figure 2 Forest plot of viscosupplementation versus saline controls on knee pain at 14 to 26 weeks.

Abbreviations: $\mathrm{Cl}$, confidence interval; SMD, standardized mean difference.

specifically smaller sample size and lower study quality, were associated with greater knee pain (Table 4) and function (Table 5) treatment effects. Studies with higher proportions of female patients yielded better knee function outcomes. No other factors including age, BMI, symptom duration, Kellgren-Lawrence grade, or industry funding were associated with knee pain or function outcomes. No factors influenced the risk of SAEs (Table 6).

\section{Sensitivity analyses}

In order to explore the impact of single studies on the main outcomes, we performed a "one study removed" analysis by

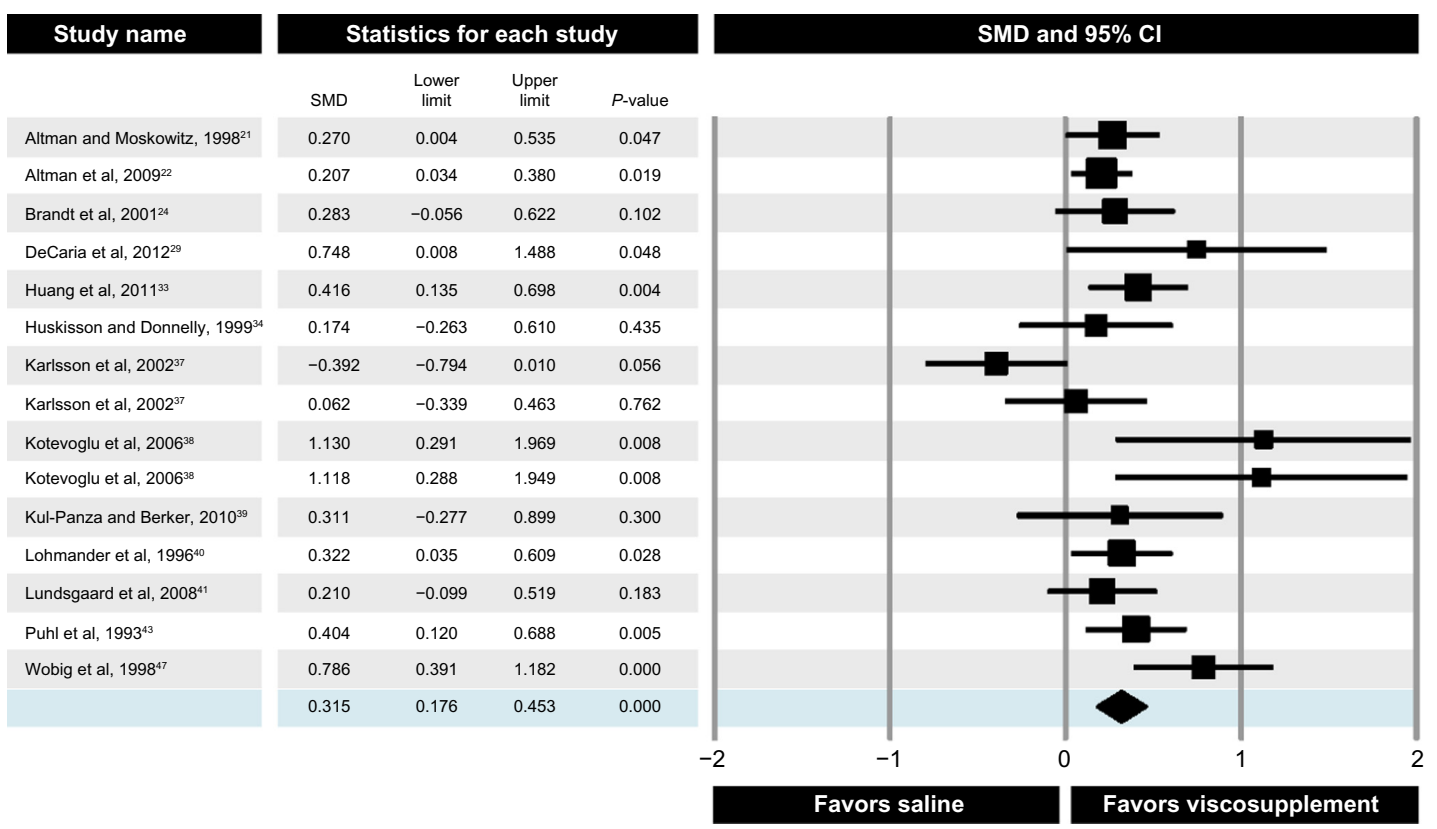

Figure 3 Forest plot of viscosupplementation versus saline controls on knee function at 14 to 26 weeks. Abbreviations: $\mathrm{Cl}$, confidence interval; SMD, standardized mean difference. 


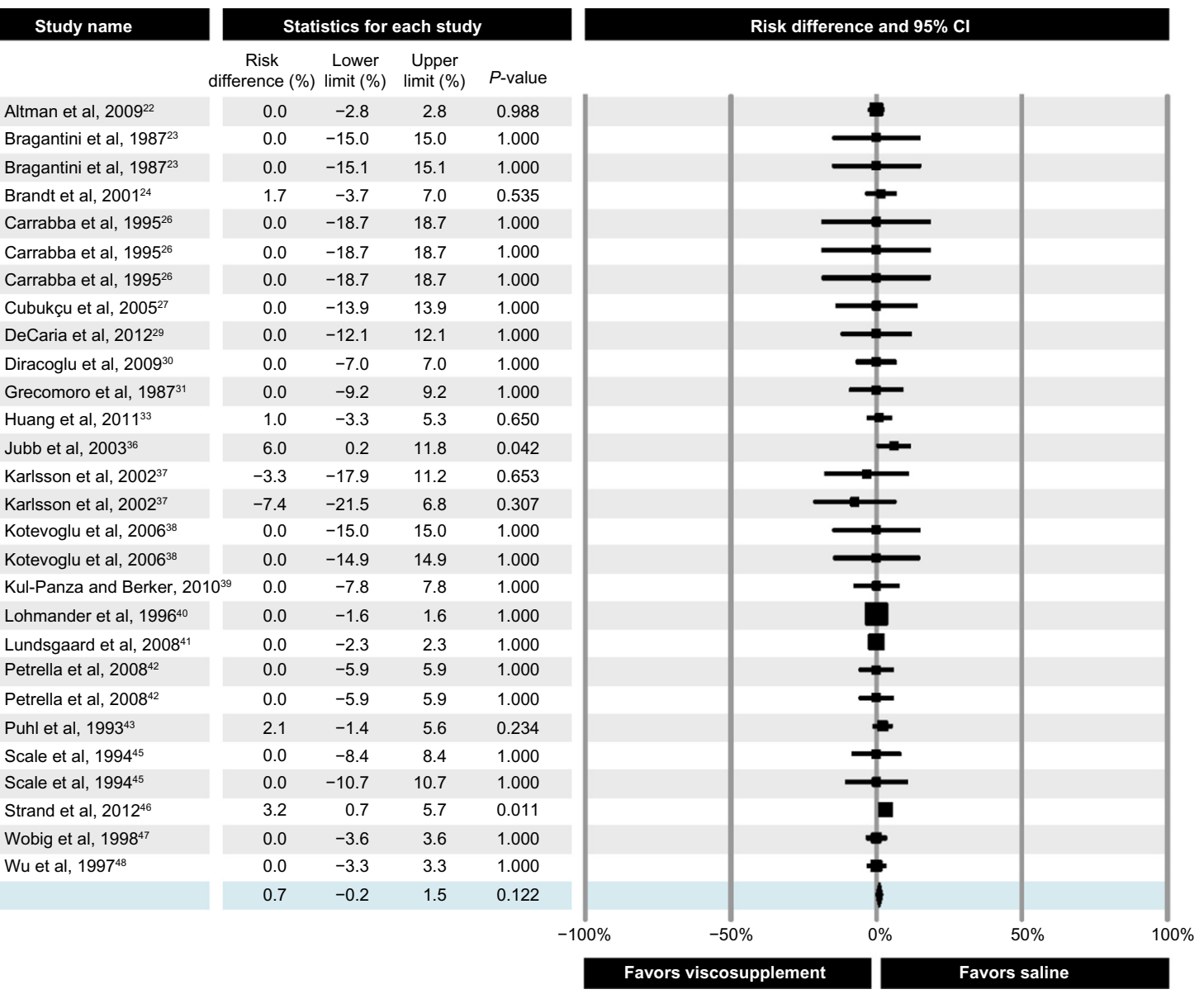

Figure 4 Forest plot of viscosupplementation versus saline controls on risk of serious adverse events. Abbreviation: $\mathrm{Cl}$, confidence interval.

reestimating the meta-analysis after removing one study at a time for each main outcome. No single study had a major influence on any outcome (File S21). Additionally, we performed an analysis of safety outcomes using the odds ratio with no correction for zero total event trials as the statistic of interest, the method used in the meta-analysis of Rutjes et al. ${ }^{12}$ This analysis demonstrated no differences in risk between groups for any outcome (File S22). Overall, the results of the sensitivity analyses corroborated those of the main meta-analysis.

\section{Comparison of US- versus non-US-approved viscosupplements}

We extended the original literature search using the same methodology to include saline-controlled studies of nonUS-approved viscosupplements and compared outcomes to those of US-approved viscosupplements. Nine studies of non-US-approved viscosupplements were included in this analysis. ${ }^{42,50-57}$ All knee pain and function treatment effects with non-US-approved viscosupplements were negligible to small (SMD range: -0.02 to 0.26 ) and were statistically inferior to US-approved products at the 4 to 13 week window, but not at 14 to 26 weeks. There were no statistically significant RDs in any safety outcome between US- and non-US-approved viscosupplements (File S23).

\section{Discussion}

We conducted the first systematic review and meta-analysis of US-approved HA products on knee OA symptoms. Overall, we conclude that intra-articular injection of US-approved viscosupplements is safe and efficacious in patients with symptomatic knee OA. Several systematic reviews and metaanalyses have been published on this topic, with the SMD of viscosupplementation versus a control group for efficacy outcomes ranging from 0.0 to $0.46 .^{5,6,9,12,58}$ For comparison, the saline-adjusted SMD in the current meta-analysis ranged from 0.32 to 0.43 , depending on outcome and time window. Another notable finding was that, while safe, the efficacy of non-US-approved viscosupplements was poor. The reason for the differences in treatment effect with US- versus 
Study name

\begin{tabular}{|c|c|c|c|c|}
\hline & \\
\hline & $\begin{array}{c}\text { Risk } \\
\text { difference (\%) }\end{array}$ & $\begin{array}{l}\text { Lower } \\
\text { limit (\%) }\end{array}$ & $\begin{array}{l}\text { Upper } \\
\text { limit (\%) }\end{array}$ & $P$-value \\
\hline Altman and Moskowitz, $1998^{21}$ & 3.1 & -0.0 & 6.2 & 0.053 \\
\hline Altman et al, $2009^{22}$ & 1.7 & -1.0 & 4.4 & 0.213 \\
\hline Bragantini et al, $1987^{23}$ & 0.0 & -15.0 & 15.0 & 1.000 \\
\hline Bragantini et al, $1987^{23}$ & 0.0 & -15.1 & 15.1 & 1.000 \\
\hline Carrabba et al, $1995^{26}$ & 0.0 & -18.7 & 18.7 & 1.000 \\
\hline Carrabba et al, $1995^{26}$ & 0.0 & -18.7 & 18.7 & 1.000 \\
\hline Carrabba et al, $1995^{26}$ & 0.0 & -18.7 & 18.7 & 1.000 \\
\hline Cubukçu et al, $2005^{27}$ & 0.0 & -13.9 & 13.9 & 1.000 \\
\hline DeCaria et al, $2012^{29}$ & 0.0 & -12.1 & 12.1 & 1.000 \\
\hline Diracoglu et al, $2009^{30}$ & 0.0 & -7.0 & 7.0 & 1.000 \\
\hline Grecomoro et al, $1987^{31}$ & 0.0 & -9.2 & 9.2 & 1.000 \\
\hline Huang et al, $2011^{33}$ & 0.0 & -1.9 & 1.9 & 1.000 \\
\hline Huskisson and Donnelly, 1999 & 2.0 & -4.7 & 8.7 & 0.557 \\
\hline Jørgensen et al, $2010^{35}$ & 0.0 & -1.2 & 1.2 & 1.000 \\
\hline Jubb et al, $2003^{36}$ & 4.2 & -0.0 & 8.4 & 0.051 \\
\hline Karlsson et al, $2002^{37}$ & -0.8 & -7.4 & 5.8 & 0.810 \\
\hline Karlsson et al, $2002^{37}$ & -1.8 & -8.1 & 4.4 & 0.560 \\
\hline Kul-Panza and Berker, $2010^{39}$ & 0.0 & -0.8 & 7.8 & 1.000 \\
\hline Lohmander et al, $1996^{40}$ & -2.5 & -6.7 & 1.8 & 0.252 \\
\hline Lundsgaard et al, $2008^{41}$ & 0.0 & -2.3 & 2.3 & 1.000 \\
\hline Petrella et al, $2008^{42}$ & 0.0 & -5.9 & 5.9 & 1.000 \\
\hline Petrella et al, $2008^{42}$ & 0.0 & -5.9 & 5.9 & 1.000 \\
\hline Puhl et al, $1993^{43}$ & -2.0 & -5.4 & 1.4 & 0.243 \\
\hline Rolf et al, $2005^{44}$ & 1.1 & -3.2 & 5.4 & 0.608 \\
\hline Rolf et al, $2005^{44}$ & 3.3 & -1.9 & 8.5 & 0.213 \\
\hline Sala and Miguel, $1995^{49}$ & 0.0 & -9.2 & 9.2 & 1.000 \\
\hline Scale et al, $1994^{45}$ & 0.0 & -8.4 & 8.4 & 1.000 \\
\hline Scale et al, $1994^{45}$ & 0.0 & -10.7 & 10.7 & 1.000 \\
\hline Strand et al, $2012^{46}$ & 0.0 & -1.2 & 1.2 & 1.000 \\
\hline Wobig et al, $1998^{47}$ & 0.0 & -3.6 & 3.6 & 1.000 \\
\hline Wu et al, $1997^{48}$ & 0.0 & -3.3 & 3.3 & 1.000 \\
\hline & 0.2 & -0.4 & 0.8 & 0.459 \\
\hline
\end{tabular}

Risk difference and $95 \% \mathrm{CI}$

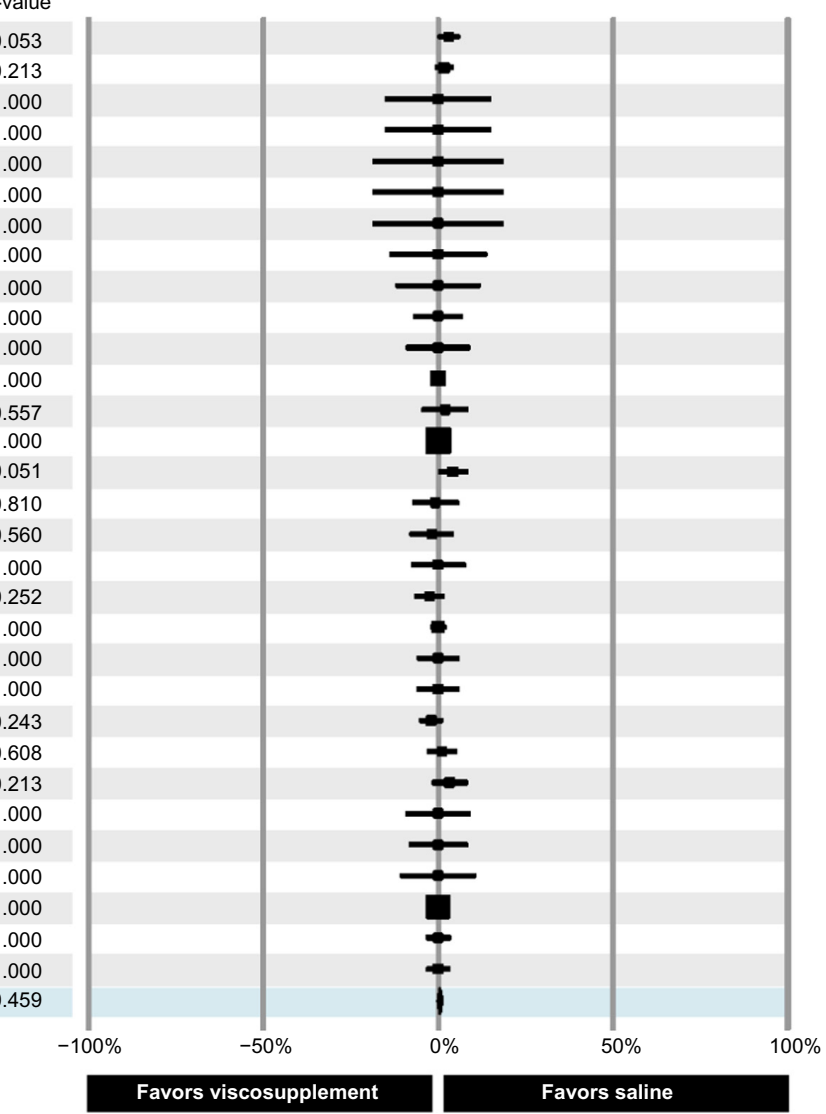

Figure 5 Forest plot of viscosupplementation versus saline controls on risk of adverse event-related patient withdrawals.

Abbreviation: $\mathrm{Cl}$, confidence interval.

non-US-approved viscosupplements is unknown, but may be related to the stringency of regulatory and clinical trial requirements among countries. Additional research in this area is warranted.

The use of the effect size statistic to infer clinically meaningful changes in efficacy outcomes is frequently misinterpreted. For example, the control group-corrected treatment effect of viscosupplementation is frequently cited in meta-analyses. However, it would be erroneous to estimate clinical relevance or responder rates from this statistic. In order to estimate the clinical benefit to a patient, the pretreatment to posttreatment effect size in the viscosupplement group, not the control group-corrected effect size, is the most appropriate statistic. Rutjes et a ${ }^{12}{ }^{12}$ report an effect size of 0.37 (corrected for control changes) and then erroneously state that this is equivalent to an improvement in knee pain of $0.9 \mathrm{~cm}$ on a $10 \mathrm{~cm}$ scale. In fact, Rutjes et al's ${ }^{12}$ reference for this statement ${ }^{59}$ was derived from other papers ${ }^{60-63}$ which clearly state that pretreatment to posttreatment treatment effects, not control group-corrected treatment effects, should be used to make this calculation.

The current meta-analysis is the only known report to cite the pretreatment to posttreatment SMD. Injection of US-approved viscosupplements resulted in an SMD for knee pain of 1.37 at 4 to 13 weeks and 1.14 at 14 to 26 weeks. SMDs for knee function were 1.16 and 1.07 , respectively. These values represent very large treatment effects for viscosupplementation and are independent of changes reported in saline control groups. Using the assumption that a standardized effect size of 0.37 equates to a $0.9 \mathrm{~cm}$ improvement (on a $10 \mathrm{~cm}$ scale) in knee pain or function, the pretreatment to posttreatment treatment effects for US-approved viscosupplements would be equal to improvements of 2.8 to $3.3 \mathrm{~cm}$ for knee pain and 2.6 to $2.8 \mathrm{~cm}$ for knee function (on a $10 \mathrm{~cm}$ scale). Importantly, the lower-bound confidence limits for all efficacy outcomes (ranging from 0.84 to 1.12) are substantially higher than the minimum threshold for clinical importance (0.37). 
Table 4 Subgroup analysis of study- and patient-related factors on saline-corrected knee pain

\begin{tabular}{|c|c|c|c|}
\hline Factor & SMD & $95 \% \mathrm{Cl}$ & $P$-value \\
\hline \multicolumn{4}{|l|}{ Age } \\
\hline$\geq 65$ years $(\mathrm{n}=\mathrm{I} \mathrm{I})$ & 0.27 & 0.03 to 0.5 I & \multirow[t]{2}{*}{0.20} \\
\hline$<65$ years $(n=23)$ & 0.46 & 0.29 to 0.64 & \\
\hline \multicolumn{4}{|l|}{ Body mass index } \\
\hline$\geq 30 \mathrm{~kg} / \mathrm{m}^{2}(\mathrm{n}=5)$ & 0.28 & 0.00 to 0.56 & \multirow[t]{2}{*}{0.72} \\
\hline$<30 \mathrm{~kg} / \mathrm{m}^{2}(\mathrm{n}=18)$ & 0.34 & 0.17 to 0.51 & \\
\hline \multicolumn{4}{|l|}{ Female proportion } \\
\hline$\geq 67 \%(n=15)$ & 0.54 & 0.30 to 0.77 & \multirow[t]{2}{*}{0.15} \\
\hline$<67 \%(\mathrm{n}=19)$ & 0.32 & 0.14 to 0.49 & \\
\hline \multicolumn{4}{|l|}{ Symptom duration } \\
\hline$\geq 5$ years $(n=9)$ & 0.35 & 0.10 to 0.60 & \multirow[t]{2}{*}{0.07} \\
\hline$<5$ years $(n=15)$ & 0.66 & 0.43 to 0.89 & \\
\hline \multicolumn{4}{|l|}{ Kellgren-Lawrence grade } \\
\hline$\geq 3(n=6)$ & 0.07 & -0.28 to 0.42 & \multirow[t]{2}{*}{0.06} \\
\hline$<3(\mathrm{n}=12)$ & 0.47 & 0.24 to 0.70 & \\
\hline \multicolumn{4}{|c|}{ Kellgren-Lawrence grade IV } \\
\hline$\geq$ any $(\mathrm{n}=6)$ & 0.11 & -0.24 to 0.46 & \multirow[t]{2}{*}{0.25} \\
\hline$<$ none $(\mathrm{n}=\mathrm{I} \mathrm{I})$ & 0.35 & 0.14 to 0.57 & \\
\hline \multicolumn{4}{|l|}{ Total sample size } \\
\hline$\geq 100(n=14)$ & 0.17 & 0.01 to 0.33 & \multirow[t]{2}{*}{$<0.00 \mathrm{I}$} \\
\hline$<100(n=20)$ & 0.67 & 0.47 to 0.86 & \\
\hline \multicolumn{4}{|l|}{ Jadad score } \\
\hline$\geq 3(n=30)$ & 0.34 & 0.20 to 0.48 & \multirow[t]{2}{*}{0.03} \\
\hline$<3(n=4)$ & 0.87 & 0.42 to 1.33 & \\
\hline \multicolumn{4}{|l|}{ Industry funding } \\
\hline Yes or unclear $(n=32)$ & $0.4 I$ & 0.27 to 0.56 & \multirow[t]{2}{*}{0.21} \\
\hline No $(n=2)$ & 0.04 & -0.52 to $0.6 \mathrm{I}$ & \\
\hline
\end{tabular}

Abbreviations: $\mathrm{Cl}$, confidence interval; SMD, standardized mean difference.

We found that neither US-approved nor non-US-approved viscosupplements were associated with increased safety risks. These findings are in contrast to those of Rutjes et al ${ }^{12}$ who concluded that viscosupplementation increased the risk of SAEs and AE-related patient withdrawals. However, there are several important distinctions between the two meta-analyses that are worth mentioning. First, although the calculated risk of SAEs was marginally higher with viscosupplementation versus controls in the Rutjes study, the treatment association of the reported SAE was not considered. In our analysis, no SAE was related to treatment. Second, the safety analysis and conclusions in the Rutjes paper were heavily influenced by inclusion of unpublished, unverifiable data. In contrast, we only included data from full-text manuscripts published in peer-reviewed journals. Lastly, Rutjes et al analyzed all safety data using an odds ratio without a correction factor for zero total event trials, a statistic that excludes zero total event trials. Considering that 30 of $38 \mathrm{SAE}$ treatment effects in the current metaanalysis reported zero total events, use of such an analysis is inadvisable since most data are disregarded.
Table 5 Subgroup analysis of study- and patient-related factors on saline-corrected knee function

\begin{tabular}{|c|c|c|c|}
\hline Factor & SMD & $95 \% \mathrm{Cl}$ & $P$-value \\
\hline \multicolumn{4}{|l|}{ Age } \\
\hline$\geq 65$ years $(n=7)$ & 0.17 & -0.07 to 0.40 & \multirow[t]{2}{*}{0.07} \\
\hline$<65$ years $(n=17)$ & 0.42 & 0.26 to 0.59 & \\
\hline \multicolumn{4}{|l|}{ Body mass index } \\
\hline$\geq 30 \mathrm{~kg} / \mathrm{m}^{2}(\mathrm{n}=4)$ & 0.28 & -0.01 to 0.56 & \multirow[t]{2}{*}{0.91} \\
\hline$<30 \mathrm{~kg} / \mathrm{m}^{2}(\mathrm{n}=15)$ & 0.30 & 0.13 to 0.46 & \\
\hline \multicolumn{4}{|l|}{ Female proportion } \\
\hline$\geq 67 \%(n=9)$ & 0.63 & 0.36 to 0.89 & \multirow[t]{2}{*}{0.01} \\
\hline$<67 \%(n=15)$ & 0.25 & 0.10 to 0.39 & \\
\hline \multicolumn{4}{|l|}{ Symptom duration } \\
\hline$\geq 5$ years $(n=6)$ & 0.30 & 0.02 to 0.59 & \multirow[t]{2}{*}{0.15} \\
\hline$<5$ years $(\mathrm{n}=\mathrm{II})$ & 0.58 & 0.33 to 0.83 & \\
\hline \multicolumn{4}{|l|}{ Kellgren-Lawrence grade } \\
\hline$\geq 3(\mathrm{n}=4)$ & 0.45 & 0.09 to $0.8 \mathrm{I}$ & \multirow[t]{2}{*}{0.86} \\
\hline$<3(\mathrm{n}=8)$ & 0.41 & 0.16 to 0.66 & \\
\hline \multicolumn{4}{|l|}{ Kellgren-Lawrence grade IV } \\
\hline$\geq$ any $(\mathrm{n}=2)$ & 0.25 & -0.17 to 0.67 & \multirow[t]{2}{*}{0.78} \\
\hline$<$ none $(\mathrm{n}=9)$ & 0.31 & 0.13 to 0.50 & \\
\hline \multicolumn{4}{|l|}{ Total sample size } \\
\hline$\geq 100(n=13)$ & 0.22 & 0.08 to 0.35 & \multirow[t]{2}{*}{0.001} \\
\hline$<100(n=11)$ & 0.69 & 0.44 to 0.93 & \\
\hline \multicolumn{4}{|l|}{ Jadad score } \\
\hline$\geq 3(\mathrm{n}=2 \mathrm{I})$ & 0.28 & 0.15 to 0.40 & \multirow[t]{2}{*}{0.002} \\
\hline$<3(n=3)$ & 1.05 & 0.57 to 1.52 & \\
\hline \multicolumn{4}{|l|}{ Industry funding } \\
\hline Yes or unclear $(n=22)$ & 0.35 & 0.21 to 0.49 & \multirow[t]{2}{*}{0.86} \\
\hline No $(n=2)$ & 0.30 & -0.18 to 0.78 & \\
\hline
\end{tabular}

Abbreviations: $\mathrm{Cl}$, confidence interval; SMD, standardized mean difference.

Our meta-analysis is associated with several issues that may influence interpretation. Most, but not all, studies excluded patients with end-stage (Kellgren-Lawrence grade IV or equivalent) knee OA and, therefore, the efficacy of viscosupplements in these patients cannot be determined. Due to sample size considerations, we did not attempt to analyze treatment effects by viscosupplement type or molecular weight. Lastly, efficacy outcomes were inconsistent across studies and influenced by study design factors and publication bias. Strengths of this meta-analysis are inclusion of only randomized, saline-controlled trials, structured data extraction methodology, inclusion of all zero total event trials in safety analyses, and sensitivity analyses that accounted for choice of statistical test and potentially influential studies. Finally, it should be noted that our group previously published a brief summary of main findings from this meta-analysis. ${ }^{64}$ The current paper extends that initial work by providing a comprehensive and detailed accounting of additional aspects of the meta-analysis not previously reported, including the detailed search strategy, PRISMA flow diagram, characteristics and quality assessment of included studies, detailed forest 
Table 6 Subgroup analysis of study- and patient-related factors on serious adverse events

\begin{tabular}{|c|c|c|c|}
\hline Factor & RD (\%) & $95 \% \mathrm{Cl}(\%)$ & $P$-value \\
\hline \multicolumn{4}{|l|}{ Age } \\
\hline$\geq 65$ years $(n=10)$ & 0.1 & -1.4 to 1.6 & 0.39 \\
\hline$<65$ years $(n=18)$ & 0.9 & -0.1 to 1.9 & \\
\hline \multicolumn{4}{|l|}{ Body mass index } \\
\hline$\geq 30 \mathrm{~kg} / \mathrm{m}^{2}(\mathrm{n}=5)$ & 1.0 & -1.0 to 3.1 & 0.75 \\
\hline$<30 \mathrm{~kg} / \mathrm{m}^{2}(\mathrm{n}=15)$ & 0.7 & -0.3 to 1.7 & \\
\hline \multicolumn{4}{|l|}{ Female proportion } \\
\hline$\geq 67 \%(n=12)$ & 1.5 & -1.0 to 4.1 & 0.48 \\
\hline$<67 \%(\mathrm{n}=16)$ & 0.6 & -0.3 to 1.5 & \\
\hline \multicolumn{4}{|l|}{ Symptom duration } \\
\hline$\geq 5$ years $(n=7)$ & 0.5 & -1.1 to 2.1 & 0.26 \\
\hline$<5$ years $(n=13)$ & 1.7 & 0.2 to 3.3 & \\
\hline \multicolumn{4}{|l|}{ Kellgren-Lawrence grade } \\
\hline$\geq 3(n=5)$ & 0.0 & -1.7 to 1.7 & 0.053 \\
\hline$<3(\mathrm{n}=9)$ & 2.4 & 0.7 to 4.2 & \\
\hline \multicolumn{4}{|c|}{ Kellgren-Lawrence grade IV } \\
\hline$\geq$ any $(n=4)$ & 0.0 & -2.2 to 2.2 & 0.15 \\
\hline$<$ none $(\mathrm{n}=7)$ & 2.0 & 0.4 to 3.6 & \\
\hline \multicolumn{4}{|l|}{ Total sample size } \\
\hline$\geq 100(n=12)$ & 0.8 & -0.1 to 1.7 & 0.57 \\
\hline$<100(\mathrm{n}=16)$ & 0.0 & -2.4 to 2.4 & \\
\hline \multicolumn{4}{|l|}{ Jadad score } \\
\hline$\geq 3(n=25)$ & 0.7 & -2.0 to 1.5 & 0.83 \\
\hline$<3(n=3)$ & 0.0 & -0.6 to 0.6 & \\
\hline \multicolumn{4}{|l|}{ Industry funding } \\
\hline Yes or unclear $(n=26)$ & 0.8 & -0.1 to 1.7 & 0.53 \\
\hline No $(n=2)$ & 0.0 & -2.3 to 2.3 & \\
\hline
\end{tabular}

Abbreviations: $\mathrm{Cl}$, confidence interval; $\mathrm{RD}$, risk difference.

plots and bias plots for all safety and efficacy outcomes, and results of subgroup and sensitivity analyses.

\section{Conclusion}

Intra-articular injection of US-approved viscosupplements is safe and efficacious through 26 weeks in patients with symptomatic knee OA. Limitations of this meta-analysis were significant heterogeneity in efficacy outcomes among included studies and smaller treatment effects in higher quality trials.

\section{Author contributions}

LEM contributed to study design and conception, literature search, data extraction, data analysis, data interpretation, drafting of the manuscript, and provided critical revision of the manuscript for intellectual content. JEB contributed to study design and conception, data extraction, data interpretation, drafting of the manuscript, and provided critical revision of the manuscript for intellectual content. VS, LFM, and WRB contributed to study design and conception, drafting of the manuscript and provided critical revision of the manuscript for intellectual content. All authors read and provided final approval of the version to be published. All authors agree to be accountable for all aspects of the work in ensuring that questions related to the accuracy or integrity of any part of the work are appropriately investigated and resolved.

\section{Disclosure}

We disclose that financial support for this work was provided by the HA Viscosupplement Coalition (Bioventus LLC, Durham, NC, USA; DePuy Synthes Mitek Sports Medicine, Raynham, MA, USA; Ferring Pharmaceuticals Inc., Parsippany, NJ, USA; Fidia Pharma USA, Inc., Parsippany, NJ, USA; Zimmer, Inc., Warsaw, IN, USA). The funding agency was not involved in data collection, data analysis, data interpretation, or manuscript development. The authors report no other conflicts of interest in this work.

\section{References}

1. Dieppe PA, Lohmander LS. Pathogenesis and management of pain in osteoarthritis. Lancet. 2005;365(9463):965-973.

2. Dahl LB, Dahl IM, Engström-Laurent A, Granath K. Concentration and molecular weight of sodium hyaluronate in synovial fluid from patients with rheumatoid arthritis and other arthropathies. Ann Rheum Dis. 1985;44(12):817-822.

3. Smith MM, Ghosh P. The synthesis of hyaluronic acid by human synovial fibroblasts is influenced by the nature of the hyaluronate in the extracellular environment. Rheumatol Int. 1987;7(3): 113-122.

4. Goldberg VM, Buckwalter JA. Hyaluronans in the treatment of osteoarthritis of the knee: evidence for disease-modifying activity. Osteoarthritis Cartilage. 2005;13(3):216-224.

5. Arrich J, Piribauer F, Mad P, Schmid D, Klaushofer K, Müllner M. Intra-articular hyaluronic acid for the treatment of osteoarthritis of the knee: systematic review and meta-analysis. CMAJ. 2005;172(8): 1039-1043.

6. Bannuru RR, Natov NS, Dasi UR, Schmid CH, McAlindon TE. Therapeutic trajectory following intra-articular hyaluronic acid injection in knee osteoarthritis - meta-analysis. Osteoarthritis Cartilage. 2011; 19(6):611-619.

7. Bannuru RR, Natov NS, Obadan IE, Price LL, Schmid CH, McAlindon TE. Therapeutic trajectory of hyaluronic acid versus corticosteroids in the treatment of knee osteoarthritis: a systematic review and meta-analysis. Arthritis Rheum. 2009;61(12):1704-1711.

8. Colen S, van den Bekerom MP, Mulier M, Haverkamp D. Hyaluronic acid in the treatment of knee osteoarthritis: a systematic review and meta-analysis with emphasis on the efficacy of different products. BioDrugs. 2012;26(4):257-268.

9. Lo GH, LaValley M, McAlindon T, Felson DT. Intra-articular hyaluronic acid in treatment of knee osteoarthritis: a meta-analysis. JAMA. 2003;290(23):3115-3121.

10. Reichenbach S, Blank S, Rutjes AW, et al. Hylan versus hyaluronic acid for osteoarthritis of the knee: a systematic review and meta-analysis. Arthritis Rheum. 2007;57(8):1410-1418.

11. Wang CT, Lin J, Chang CJ, Lin YT, Hou SM. Therapeutic effects of hyaluronic acid on osteoarthritis of the knee. A meta-analysis of randomized controlled trials. J Bone Joint Surg Am. 2004;86-A(3): $538-545$.

12. Rutjes AW, Jüni $P$, da Costa BR, Trelle $S$, Nüesch E, Reichenbach $S$. Viscosupplementation for osteoarthritis of the knee: a systematic review and meta-analysis. Ann Intern Med. 2012;157(3):180-191. 
13. Liberati A, Altman DG, Tetzlaff J, et al. The PRISMA statement for reporting systematic reviews and meta-analyses of studies that evaluate health care interventions: explanation and elaboration. Ann Intern Med. 2009;151(4):W65-W94.

14. Jadad AR, Moore RA, Carroll D, et al. Assessing the quality of reports of randomized clinical trials: is blinding necessary? Control Clin Trials. 1996;17(1):1-12.

15. Juhl C, Lund H, Roos EM, Zhang W, Christensen R. A hierarchy of patient-reported outcomes for meta-analysis of knee osteoarthritis trials empirical evidence from a survey of high impact journals. Arthritis. Epub June 26, 2012.

16. Cohen J. Statistical Power Analysis for the Behavioral Sciences. Hillside, NJ: Lawrence Erlbaum Associates; 1988.

17. Friedrich JO, Adhikari NK, Beyene J. Inclusion of zero total event trials in meta-analyses maintains analytic consistency and incorporates all available data. BMC Med Res Methodol. 2007;7:5

18. Higgins JPT, Green S, editors. Cochrane Handbook for Systematic Reviews of Interventions, Version 5.1.0 [updated March 2011]. The Cochrane Collaboration; 2011. Available from: http://www.cochranehandbook.org. Accessed February 19, 2014.

19. Higgins JP, Thompson SG, Deeks JJ, Altman DG. Measuring inconsistency in meta-analyses. BMJ. 2003;327(7414):557-560.

20. Egger M, Davey Smith G, Schneider M, Minder C. Bias in metaanalysis detected by a simple, graphical test. BMJ. 1997;315(7109): 629-634.

21. Altman RD, Moskowitz R. Intraarticular sodium hyaluronate (Hyalgan) in the treatment of patients with osteoarthritis of the knee: a randomized clinical trial. Hyalgan Study Group. J Rheumatol. 1998;25(11) 2203-2212.

22. Altman RD, Rosen JE, Bloch DA, Hatoum HT, Korner P. A doubleblind, randomized, saline-controlled study of the efficacy and safety of EUFLEXXA for treatment of painful osteoarthritis of the knee, with an open-label safety extension (the FLEXX trial). Semin Arthritis Rheum 2009;39(1):1-9.

23. Bragantini A, Cassini M, de Bastiani G, Perbellini A. Controlled single-blind trial of intra-articularly injected hyaluronic acid (HyalganÒ*) in osteo-arthritis of the knee. Clin Trials J. 1987;24(4): 333-340.

24. Brandt KD, Block JA, Michalski JP, Moreland LW, Caldwell JR, Lavin PT. Efficacy and safety of intraarticular sodium hyaluronate in knee osteoarthritis. ORTHOVISC Study Group. Clin Orthop Relat Res. 2001;(385):130-143.

25. Bunyaratavej N, Chan KM, Subramanian N. Treatment of painful osteoarthritis of the knee with hyaluronic acid. Results of a multicenter Asian study. J Med Assoc Thai. 2001;84(Suppl 2):S576-S581.

26. Carrabba M, Paresce E, Angelini M, Re KA, Torchiana EEM, Perbellini A. The safety and efficacy of different dose schedules of hyaluronic acid in the treatment of painful osteoarthritis of the knee with joint effusion. Eur J Rheumatol Inflamm. 1995;15(1):25-31.

27. Cubukçu D, Ardiç F, Karabulut N, Topuz O. Hylan G-F 20 efficacy on articular cartilage quality in patients with knee osteoarthritis: clinical and MRI assessment. Clin Rheumatol. 2005;24(4):336-341.

28. Day R, Brooks P, Conaghan PG, Petersen M; Multicenter Trial Group. A double blind, randomized, multicenter, parallel group study of the effectiveness and tolerance of intraarticular hyaluronan in osteoarthritis of the knee. J Rheumatol. 2004;31(4):775-782.

29. DeCaria JE, Montero-Odasso M, Wolfe D, Chesworth BM, Petrella RJ. The effect of intra-articular hyaluronic acid treatment on gait velocity in older knee osteoarthritis patients: a randomized, controlled study. Arch Gerontol Geriatr. 2012;55(2):310-315.

30. Diracoglu D, Vural M, Baskent A, Dikici F, Aksoy C. The effect of viscosupplementation on neuromuscular control of the knee in patients with osteoarthritis. J Back Musculoskelet Rehabil. 2009; 22(1):1-9.

31. Grecomoro G, Martorana U, Di Marco C. Intra-articular treatment with sodium hyaluronate in gonarthrosis: a controlled clinical trial versus placebo. Pharmatherapeutica. 1987;5(2):137-141.
32. Henderson EB, Smith EC, Pegley F, Blake DR. Intra-articular injections of $750 \mathrm{kD}$ hyaluronan in the treatment of osteoarthritis: a randomised single centre double-blind placebo-controlled trial of 91 patients demonstrating lack of efficacy. Ann Rheum Dis. 1994;53(8): $529-534$.

33. Huang TL, Chang CC, Lee CH, Chen SC, Lai CH, Tsai CL. Intra-articular injections of sodium hyaluronate $\left(\mathrm{Hyalgan}^{\circledR}\right)$ in osteoarthritis of the knee. A randomized, controlled, double-blind, multicenter trial in the Asian population. BMC Musculoskelet Disord. 2011;12:221.

34. Huskisson EC, Donnelly S. Hyaluronic acid in the treatment of osteoarthritis of the knee. Rheumatology (Oxford). 1999;38(7): 602-607.

35. Jørgensen A, Stengaard-Pedersen K, Simonsen O, et al. Intra-articular hyaluronan is without clinical effect in knee osteoarthritis: a multicentre, randomised, placebo-controlled, double-blind study of 337 patients followed for 1 year. Ann Rheum Dis. 2010;69(6): 1097-1102.

36. Jubb RW, Piva S, Beinat L, Dacre J, Gishen P. A one-year, randomised, placebo (saline) controlled clinical trial of 500-730 kDa sodium hyaluronate (Hyalgan) on the radiological change in osteoarthritis of the knee. Int J Clin Pract. 2003;57(6):467-474.

37. Karlsson J, Sjögren LS, Lohmander LS. Comparison of two hyaluronan drugs and placebo in patients with knee osteoarthritis. A controlled, randomized, double-blind, parallel-design multicentre study. Rheumatology (Oxford). 2002;41(11):1240-1248.

38. Kotevoglu N, Iyibozkurt PC, Hiz O, Toktas H, Kuran B. A prospective randomised controlled clinical trial comparing the efficacy of different molecular weight hyaluronan solutions in the treatment of knee osteoarthritis. Rheumatol Int. 2006;26(4):325-330.

39. Kul-Panza E, Berker N. Is hyaluronate sodium effective in the management of knee osteoarthritis? A placebo-controlled double-blind study. Minerva Med. 2010;101(2):63-72.

40. Lohmander LS, Dalén N, Englund G, et al. Intra-articular hyaluronan injections in the treatment of osteoarthritis of the knee: a randomised, double blind, placebo controlled multicentre trial. Hyaluronan Multicentre Trial Group. Ann Rheum Dis. 1996;55(7):424-431.

41. Lundsgaard C, Dufour N, Fallentin E, Winkel P, Gluud C. Intra-articular sodium hyaluronate $2 \mathrm{~mL}$ versus physiological saline $20 \mathrm{~mL}$ versus physiological saline $2 \mathrm{~mL}$ for painful knee osteoarthritis: a randomized clinical trial. Scand J Rheumatol. 2008;37(2):142-150.

42. Petrella RJ, Cogliano A, Decaria J. Combining two hyaluronic acids in osteoarthritis of the knee: a randomized, double-blind, placebocontrolled trial. Clin Rheumatol. 2008;27(8):975-981.

43. Puhl W, Bernau A, Greiling H, et al. Intra-articular sodium hyaluronate in osteoarthritis of the knee: a multicenter, double-blind study. Osteoarthritis Cartilage. 1993;1(4):233-241.

44. Rolf CG, Engstrom B, Ohrvik J, Valentin A, Lilja B, Levine DW. A comparative study of the efficacy and safety of hyaluronan viscosupplements and placebo in patients with symptomatic and arthroscopyverified cartilage pathology. J Clin Res. 2005;8:15-32.

45. Scale D, Wobig M, Wolpert W. Viscosupplementation of osteoarthritic knees with hylan: a treatment schedule study. Curr Ther Res. 1994;55: 220-232.

46. Strand V, Baraf HS, Lavin PT, Lim S, Hosokawa H. A multicenter, randomized controlled trial comparing a single intra-articular injection of Gel-200, a new cross-linked formulation of hyaluronic acid, to phosphate buffered saline for treatment of osteoarthritis of the knee. Osteoarthritis Cartilage. 2012;20(5):350-356.

47. Wobig M, Dickhut A, Maier R, Vetter G. Viscosupplementation with hylan G-F 20: a 26-week controlled trial of efficacy and safety in the osteoarthritic knee. Clin Ther. 1998;20(3):410-423.

48. Wu JJ, Shih LY, Hsu HC, Chen TH. The double-blind test of sodium hyaluronate (ARTZ) on osteoarthritis knee. Zhonghua Yi Xue Za Zhi (Taipei). 1997;59(2):99-106.

49. Sala SF, Miguel RE. Intra-articular hyaluronic acid in the treatment of osteoarthritis of the knee: a short-term study. Eur J Rheumatol Inflamm. $15,1995: 33-38$. 
50. Altman RD, Akermark C, Beaulieu AD, SchnitzerT; Durolane International Study Group. Efficacy and safety of a single intra-articular injection of nonanimal stabilized hyaluronic acid (NASHA) in patients with osteoarthritis of the knee. Osteoarthritis Cartilage. 2004;12(8): 642-649.

51. Baltzer AW, Moser C, Jansen SA, Krauspe R. Autologous conditioned serum (Orthokine) is an effective treatment for knee osteoarthritis. Osteoarthritis Cartilage. 2009;17(2):152-160.

52. Blanco FJ, Fernandez-Sueiro JL, Pinto-tasende JC, et al. Intra-articular hyaluronan treatment of patients with knee osteoarthritis waiting for replacement surgery. Open Arthritis J. 2008;1:1-7.

53. Navarro-Sarabia F, Coronel P, Collantes E; AMELIA study group. A 40-month multicentre, randomised placebo-controlled study to assess the efficacy and carry-over effect of repeated intra-articular injections of hyaluronic acid in knee osteoarthritis: the AMELIA project. Ann Rheum Dis. 2011;70(11):1957-1962.

54. Petrella RJ, DiSilvestro MD, Hildebrand C. Effects of hyaluronate sodium on pain and physical functioning in osteoarthritis of the knee: a randomized, double-blind, placebo-controlled clinical trial. Arch Intern Med. 2002;162(3):292-298.

55. Petrella RJ, Petrella M. A prospective, randomized, double-blind, placebo controlled study to evaluate the efficacy of intraarticular hyaluronic acid for osteoarthritis of the knee. J Rheumatol. 2006;33(5):951-956.

56. Pham T, Le Henanff A, Ravaud P, Dieppe P, Paolozzi L, Dougados M. Evaluation of the symptomatic and structural efficacy of a new hyaluronic acid compound, NRD101, in comparison with diacerein and placebo in a 1 year randomised controlled study in symptomatic knee osteoarthritis. Ann Rheum Dis. 2004;63(12):1611-1617.

57. Tamir E, Robinson D, Koren R, Agar G, Halperin N. Intra-articular hyaluronan injections for the treatment of osteoarthritis of the knee: a randomized, double blind, placebo controlled study. Clin Exp Rheumatol. 2001;19(3):265-270.
58. Maratea D, Fadda V, Trippoli S, Messori A. Viscosupplementation in patients with knee osteoarthritis: temporal trend of benefits assessed by meta-regression. Eur J Orthop Surg Traumatol. 2014;24(5): 829-830.

59. Wandel S, Jüni P, Tendal B, et al. Effects of glucosamine, chondroitin, or placebo in patients with osteoarthritis of hip or knee: network meta-analysis. BMJ. 2010;341:c4675.

60. Eberle E, Ottillinger B. Clinically relevant change and clinically relevant difference in knee osteoarthritis. Osteoarthritis Cartilage. 1999;7(5): 502-503.

61. Angst F, Aeschlimann A, Stucki G. Smallest detectable and minimal clinically important differences of rehabilitation intervention with their implications for required sample sizes using WOMAC and SF-36 quality of life measurement instruments in patients with osteoarthritis of the lower extremities. Arthritis Rheum. 2001;45(4):384-391.

62. Angst F, Aeschlimann A, Michel BA, Stucki G. Minimal clinically important rehabilitation effects in patients with osteoarthritis of the lower extremities. J Rheumatol. 2002;29(1):131-138.

63. Salaffi F, Stancati A, Silvestri CA, Ciapetti A, Grassi W. Minimal clinically important changes in chronic musculoskeletal pain intensity measured on a numerical rating scale. Eur J Pain. 2004;8(4):283-291.

64. Miller LE, Block JE. US-approved intra-articular hyaluronic acid injections are safe and effective in patients with knee osteoarthritis: systematic review and meta-analysis of randomized, saline-controlled trials. Clin Med Insights Arthritis Musculoskelet Disord. 2013;6: $57-63$.
Journal of Pain Research

\section{Publish your work in this journal}

The Journal of Pain Research is an international, peer-reviewed, open access, online journal that welcomes laboratory and clinical findings in the fields of pain research and the prevention and management of pain. Original research, reviews, symposium reports, hypothesis formation and commentaries are all considered for publication.

\section{Dovepress}

The manuscript management system is completely online and includes a very quick and fair peer-review system, which is all easy to use. Visit http://www.dovepress.com/testimonials.php to read real quotes from published authors. 